Recebido: 20/05/2016

Aprovado: 16/11/2016

\title{
Trânsitos políticos e intelectuais da geração 1870: um novo olhar sobre o movimento e sua relação com o repertório europeu
}

\author{
Bruno Gontyjo do Couto'
}

\begin{abstract}
Resumo: Durante algum tempo, as análises sobre a geração político-intelectual de 1870 pautaram-se no senso comum acadêmico de que o campo do pensamento no Brasil à época constituía-se como um espaço de imitação das ideias estrangeiras. Mais recentemente, essa visão foi questionada por autores como Renato Ortiz e Ângela Alonso, que apontaram para tendências de seleção e recorte das teorias e filosofias políticas que pouco tinham a ver com uma simples imitação. Dentro desse debate, o presente trabalho pretende dar um passo além e lançar um novo olhar sobre o movimento de 1870. Acreditamos que para entendê-lo, é fundamental levar em conta os processos históricos de integração modernizadora perpetrados pela II Revolução Industrial que atingiram o continente americano em cheio, constituindo-se, assim, tanto como experiência de vida quanto como temática de estudo daquela geração. A proposta deste artigo é analisar o movimento de 1870 através desse contexto global de integração - no qual estava inserido do ponto de vista brasileiro - para, então, dar conta da construção de suas perspectivas político-intelectuais a partir de uma série de trânsitos complexos e multifacetados que foram sendo realizados com o repertório intelectual-filosófico europeu.
\end{abstract}

Palavras-chave: Movimento de 1870; Pensamento social brasileiro; Circulação de ideias.

Abstract: For some decades, the analyzes on the 1870's Brazilian political and intellectual generation followed the academic common sense which uses to understand the local intellectual field from that period as a space of imitation and copy of foreign ideas. Recently, this vision was condemned by researchers as the Ortiz and Alonso, which pointed to tendencies of theoretical and political selection that had nothing to do with copy of foreign ideas. The present paper is an attempt to take a step forward in this debate and draw a new perspective about the Brazilian 1870's movement. We understand that the analysis about this movement must take into consideration the historical processes of integration and modernization disseminated by the Second Industrial Revolution which reached the whole America continent, constituting itself as a life experience as well as an object of study of that intellectual generation. The main objective of this paper is to analyze the 1870's movement through this global context of integration and, therefore, understand how they build their political and intellectual perspectives through a range of complex and diverse trades that held with the European intellectual and philosophical repertoire.

Keywords: 1870 's Brazilian movement; Brazilian social thought; Circulation of ideas.

\footnotetext{
${ }^{1}$ Professor voluntário do Departamento de Sociologia da UnB (SOL-UnB) e doutorando no Programa de PósGraduação do mesmo departamento. Membro do grupo de pesquisa Cultura, Memória e Desenvolvimento (CMD/UnB). E-mail: brunogcouto@gmail.com
} 


\section{Introdução}

Ao longo da década de 1870, o Brasil sofreu um forte impacto com a chegada de novos fluxos de modernização advindos da Europa por conta da II Revolução Industrial. A complexificação das dinâmicas comerciais, políticas e culturais entre Brasil e o mundo acaba desdobrando-se na formação de uma agenda política local voltada para a modernização das estruturas sociais nacionais com o intuito de melhor adaptar essas estruturas aos novos fluxos, bem como de aumentar sua capacidade de atraí-los. A formação dessa agenda envolveu uma série de mobilizações políticas e intelectuais entre diversos grupos locais, tendo em vista que os interesses, motivações e prerrogativas de cada um desses grupos voltava-se para um projeto de sociedade nacional e civilização.

Foi justamente sob os desafios e perspectivas desse cenário global e local que surgiu a chamada "geração de 1870". Animados pela visão científica da ordem social de Comte (muitas vezes combinada ao liberalismo de Stuart Mill e ao evolucionismo de Spencer), esses intelectuais estavam preocupados com os problemas de unificação política, com a construção do Estado-nacional em bases modernas e com a superação das heranças arcaicas do período colonial. Também estavam interessados no avanço da implantação de uma estrutura socioeconômica moderna. Sentiam-se vislumbrados com o futuro brilhante apontado pelo desenvolvimento econômico e científico europeu e com a promessa do triunfo da civilização e da modernidade. Mas também estavam atormentados pelas evidências de atraso cultural, político e econômico do país quando comparado com as potências imperialistas.

Durante muito tempo, as análises sobre essa geração político-intelectual pautaram-se no senso comum de que o campo do pensamento no Brasil à época constituía-se como um espaço de imitação das ideias estrangeiras, sobretudo europeias (Cf. ORTIZ, 2006: 27). A perspectiva propagada por críticos literários e historiadores era de que o Brasil atuava como um entreposto de produtos culturais provindos do exterior. Recentemente, essa tese vem sendo questionada por autores como Renato Ortiz e Ângela Alonso, que demonstraram os recortes e sincretismos inéditos realizados pelos autores brasileiros com base em motivações políticas locais. Inspirado nesses autores, o presente trabalho pretende lançar um novo olhar sobre o movimento de 1870, procurando entender o caráter extremamente inovador que ele portava e como sua relação com o repertório intelectual-filosófico europeu não pode ser simplificada enquanto um simples processo de recepção e imitação. Mais do que isso, pretendemos ir além das perspectivas propostas por Ortiz e Alonso, demonstrando como a 
ideia de uma "escolha motivada por questões políticas" é insuficiente para dar conta de toda a complexidade envolvida nesse processo de absorção de ideias estrangeiras. A nosso ver, tratase de mais do que imitação e importação ou escolha e sincretismo de teorias, a própria experiência, constituição e conduta desses atores esteve marcada por todo o processo de transformação e modernização vivido pelo Brasil à época e que fora em parte engendrado pelas ondas de novidade que partiam da II Revolução Industrial européia para o continente sul-americano através do Atlântico. Algo que repercutiu profundamente na relação do movimento com o repertório intelectual europeu.

Desse modo, acreditamos que qualquer análise do movimento de 1870 deve atentar para essa dinâmica complexa, centrada em um processo histórico de integração modernizadora que se constituía como experiência e como temática daquela geração. Nossa proposta é entender o contexto global de integração em que essa geração estava inserida (dentro de uma posição local-nacional), para então dar conta da construção de suas perspectivas político-intelectuais a partir dos inúmeros trânsitos complexos e multivariados que foram realizados com o repertório intelectual-filosófico europeu. A nosso ver, a perspectiva desses intelectuais procurou inserir o Brasil numa história evolucionária, lendo o momento conturbado do país como uma crise de transição na direção da civilização moderna e que deveria ser regrada por uma política científica guiada por uma vanguarda ilustrada. Através dos recursos teóricos das teorias europeias, procuravam entender a singularidade histórica brasileira e os entraves que mantinham o país em situação de atraso.

\section{Um país em transformação: contexto político e social do movimento de 1870}

A conjuntura histórica da década de 1870 é marcada por um amplo processo de mudanças estruturais: os alicerces coloniais da formação social, como a forma patrimonial do Estado e o regime de trabalho, estavam se desagregando (Cf. ALONSO, 2002: 41). A antiga ordem social, uma sociedade latifundiária sustentada por um sistema de produção de commodities agrícolas pautado no trabalho escravo, comandada por uma elite aristocrática que era separada por um abismo dos trabalhadores escravos e da pequena camada de setores médios, começava a se alterar profundamente (Cf. NEEDELL, 1993: 21). O velho mundo do Brasil-Império começava a desaparecer.

Entre 1850 e 1870, a chamada "II Revolução Industrial” (com avanços na química, elétrica, petróleo e aço) proporcionou a base tecnológica para montagem dos primeiros 
grandes complexos manufatureiros e industriais e para a rápida evolução do comércio, levando a uma dinâmica de crescimento sem precedentes na economia capitalista. Em decorrência de todo esse crescimento surgiu, por um lado, uma grande demanda por matériasprimas (de tipo animal, vegetal e mineral) e, por outro, uma pressão contínua pela ampliação do mercado consumidor de produtos industrializados. Houve um profundo desdobramento espacial do capitalismo que, através das técnicas de comunicação, transporte e comércio se expandiram por todo o globo, suplantando pouco a pouco as economias pré-capitalistas existentes fora da Europa (Cf. SEVCENKO, 1999).

O impacto sobre os países latino-americanos, ainda fortemente submetidos à influência das potências europeias, foi imediato e profundo. Com auxílio do capital europeu que avançava rapidamente sobre esses países, dada as vantagens oferecidas pelos governos locais, esses países montaram toda a infraestrutura de transporte e comunicação, além das indústrias extrativas e de beneficiamento de matérias primas, necessárias para a adaptação ao volume e ritmo de demanda do mercado europeu e americano. O intenso desenvolvimento desse capitalismo "agrário" levou à complexificação das sociedades latino-americanas, marcada por processos de urbanização concentrada, surgimento de uma estrutura de comércio de bens e serviços, além do aparecimento de novos grupos sociais, como a "burguesia agrária" e as classes urbanas.

Por outro lado, com a intensificação das interdependências sociais no contexto desse movimento de globalização econômica, o processo de integração sociocultural entre a América Latina e a Europa, existente desde o período colonial, se intensificou bastante. Nesse período, os estilos de conduta, os modos de pensar e agir, assim como as instituições do "Ocidente moderno e civilizado" foram assimilados de modos variados pelos grupos locais (principalmente pelas elites), que tentaram fundir o padrão "civilizado" com os hábitos e tradições de sua sociedade. Assim como nos demais países latino-americanos, o impacto no Brasil foi profundo, tendo repercussões na vida econômica, social, política e cultural do país.

Por conta desse processo de expansão e intensificação dos fluxos comerciais, o Brasil passou a se integrar cada vez mais na divisão internacional do trabalho através de sua "commoditie" agrícola mais valiosa, o café (nesse período, o café já representava praticamente metade das nossas exportações). A enorme expansão do comércio do país com o resto do mundo foi consequência da generalização do consumo do café na Europa e, principalmente, nos Estados Unidos. Nesse período, há uma grande expansão das lavouras de café, principalmente no noroeste paulista, e uma consequente intensificação da atividade 
mercantil e financeira que levou ao surto de prosperidade urbano-industrial das maiores cidades do país. Dentre os desdobramentos desse ciclo na vida social, destacam-se os processos de urbanização concentrada nas principais cidades, além dos respectivos processos de diferenciação da população urbana (Cf. NEEDELL, 1993: 21). A sociedade dinamizava-se. Novas classes surgiam, novas classes ascendiam, enquanto velhas classes decaíam.

De um lado, a partir desse processo de expansão econômica e complexificação social, surge uma nova classe assentada em modelos de produção e negócio capitalistas, com características mais modernas que a aristocracia rural do Império: a burguesia agrária que agora dominava o setor cafeeiro, localizada principalmente no oeste paulista. Uma classe que tinha consciência de seus objetivos e interesses e que, pouco a pouco, começava a construir um projeto de reestruturação política do país. De outro, após a vitória na Guerra do Paraguai, o exército surge como uma corporação cada vez mais forte e cada vez mais consciente de si. Crescia entre os oficiais a visão de que os militares eram um estamento cívico que havia sido provado na guerra, que merecia respeito e que devia ter sua parte no poder. Trata-se de um grupo cujas fileiras eram preenchidas pelos próprios segmentos urbanos que surgiram com o crescimento econômico de 1850-1870, filhos de funcionários urbanos ou mesmo de militares, educados nas cidades, aversos ao imoralismo político e animados pelo amor dedicado à corporação e à pátria. Uma nova força social e política que surgia dentro do próprio aparato estatal (Cf. CARDOSO, 1996: 32). Em suma, dois segmentos sociais que surgiam com extremo poderio econômico e político e que não se integravam perfeitamente ao mundo político imperial.

Do ponto de vista da vida cultural, a combinação de um cenário de transformação econômica, de respectiva diferenciação sociourbana e de abertura da agenda política culminou no florescimento de uma "nova imprensa", de cunho não oficial e movida pelos grupos mal integrados à política imperial. Segundo Alonso (Cf. 2002: 279), esses novos jornais tornaramse um espaço de crítica e reivindicação coletiva, gerando um universo mais complexo de informações e opiniões.

Em meio à agitação da vida intelectual de 1870, surgiam os protagonistas do movimento responsável pela contestação da ordem imperial e pela proposição de um projeto republicano de sociedade. Vindos muitas vezes das famílias de agricultores paulista, de militares ou classes urbanas, atentos às novas dinâmicas que se espalhavam pelo mundo a partir da Europa e chegavam ao país, os jovens estudantes e professores mais novos das academias superiores, principalmente das Faculdades de Direito de São Paulo e Recife e das 
Escolas Militar e Politécnica do Rio de Janeiro, transformaram as salas de aula, os jornais acadêmicos e os clubes estudantis nos principais centros de politização e mobilização político-intelectual de contestação ao Império a partir de 1870 (Cf. VITA, 1965: p.8). Construíram "uma crítica coletiva às instituições políticas e aos modos de pensar cristalizados como tradição político-intelectual do Segundo Reinado: o liberalismo estamental, o indianismo romântico, o catolicismo hierárquico" (ALONSO, 2002: 170).

Desse modo, essa série de mudanças e rupturas produziu uma revolta coletiva que durou de meados de 1870 até 1889 . Revolta que seria marcada pela proposição de um conjunto de reformas estruturais e pelo ataque aos fundamentos materiais e simbólicos da ordem imperial. Pouco a pouco, o mundo imperial foi sendo desafiado e contestado, dando claros sinais de desagregação ao longo desse período.

Como veremos os jovens estudantes e professores das faculdades imperiais, animados pelas doutrinas cientificistas e pela nova realidade que surgia no Velho Mundo, transformaram esses locais em centros de contestação aos fundamentos simbólicos e políticos da ordem imperial. A reforma educacional promovida pelo gabinete Rio Branco em 1875 ampliou as cadeiras de ciências e os cursos técnicos, promoveu a entrada de novos professores, além de profissionalizar o magistério (Cf. AZEVEDO, 1994: 34). De algum modo, contribuiu para criação de um espírito cada vez mais científico e cada vez menos bacharelesco e católico. A partir das faculdades de medicina, de direito e das escolas militares, surgiam as mais profundas críticas ao direito natural, rechaçando a legitimidade do direito divino, à metafísica católica, negando a religião como fator de avaliação e explicação do mundo, à visão romântica de Brasil, desmantelando a construção luso-tupi da história nacional.

\section{O movimento político-intelectual de 1870}

Os grupos que desenvolveram suas atividades políticas e intelectuais de contestação à ordem imperial, propondo uma série de reformas, a partir de meados da década de 1870 costumam ser designados pela literatura especializada através do termo "movimento de 1870", reunindo membros do Partido Liberal, membros dos clubes republicanos e abolicionistas, fazendeiros paulistas reunidos no Partido Republicano Paulista, oficiais do Exército, professores e estudantes das faculdades de direito e das escolas militares. Já os seus protagonistas intelectuais, como Joaquim Nabuco, Tobias Barreto, Alberto Sales e Benjamim Constant, são conhecidos como "geração de 1870". 
O exercício de criação de uma única referência para tantos grupos heterogêneos sempre porta a dificuldade incontornável de delineamento das semelhanças e diferenças existentes entre os elementos do conjunto. No âmbito do artigo, parece suficiente traçar as suas linhas gerais e os pontos de comunhão, reconstituindo os aspectos mais fundamentais de suas perspectivas e propostas. A novidade e a força dos discursos e práticas de todos os grupos do movimento político-intelectual de 1870 estavam na proposição de uma série de uma série de reformas sociais amplas, de cunho estrutural, abarcando instituições políticas, econômicas e sociais (abolição, a república, o Estado laico, etc.) a partir de um manancial teórico e ideológico de cunho cientificista e materialista que chegava da Europa e que portava ideais e valores de cunho "moderno" e "civilizado" (evolucionismo, darwinismo social e positivismo).

É preciso ter em mente que a capacidade do movimento de propor inovações, e mais tarde efetivar parte delas, estava fundamentada em sua base política e econômica que, sem sombra de dúvida, tinha como alicerces centrais os oficiais militares e a burguesia agrária paulista. Contudo, em nossa perspectiva, o seu aspecto mais "revolucionário" estava justamente em sua dimensão simbólica, na visão de mundo que portava e que era, de certo modo, incompatível com a base simbólica da ordem imperial. Muito além do fato de suas propostas serem bem mais radicais que as realizadas pelo Império, o caráter inovador do movimento estava justamente no conjunto de ideais e valores que portava, na base cognitiva e afetiva que os animava e que alterava radicalmente o modo de compreensão e avaliação do mundo social. A partir daí, surgirá uma imagem de sociedade que era muito diferente da ordem imperial, diferente nos próprios princípios de ordem social.

Vale a pena se deter rapidamente na análise dos grupos, visualizando suas proposições e seus pensamentos. Alonso desenvolve uma análise detalhada sobre o movimento de 1870, propondo um mapeamento sócio histórico muito rico e interessante.

A autora apresenta o movimento a partir da sua divisão em quatro grupos (liberais republicanos, novos liberais, abolicionistas positivistas e federalistas científicos) que convergiriam e divergiriam de diferentes maneiras nas propostas de reformas e no grau de prioridade de cada uma delas, variando no leque-comum que reunia: um regime político representativo, um regime de trabalho livre e modelos de produção e negócio capitalistas, um governo e uma sociedade pautados na razão e na ciência, além de formas de sociabilidade urbanas (Cf. ALONSO, 2002: 170). Nesse sentido, incorporavam de diferentes maneiras as tendências antimonárquica, antiescravista, anticatólica, antirromântica e antiliberal (Cf. idem, 
ibidem: 146). Do ponto de vista das teorias e doutrinas que os inspiravam, as adesões tinham o terreno comum do chamado cientificismo francês (principalmente, Auguste Comte e Ernest Renan) e do decadentismo português (Oliveira Martins e Teóphilo Braga), variando entre outras escolas e autores, com destaque para os ingleses Stuart Mill e Herbert Spencer (Cf. idem, ibidem: 193). Alonso argumenta que apesar da heterogeneidade das proposições e inspirações, esses grupos estariam unidos por uma "comunidade de situação", na medida em que se configuravam como segmentos sociais mais ou menos marginalizados em relação ao núcleo de poder, insatisfeitos com as desvantagens que os afligiam e engajados no exercício de contestação da ordem política, clamando por uma renovação profunda.

O grupo dos liberais republicanos era constituído pela ala mais radical dos liberais, o grupo que rompeu com o Império para compor o Clube Republicano e, mais tarde, o Partido Republicano situado na Corte. Para os liberais republicanos, os problemas enfrentados pelo país seriam consequências do "despotismo" da monarquia, uma herança que vinha desde os tempos do Brasil-colônia corrompendo o Estado. A república democrática e federativa seria o melhor modelo de governo, mais habilitado a expressar os interesses de toda uma nação, devendo substituir o sistema monárquico.

O grupo dos novos liberais era composto por outra ala dissidente do Partido Liberal, mas que ainda manteve seu apoio ao Imperador. Uma das causas mais importantes do grupo foi a abolição, defendida de modo primoroso por Joaquim Nabuco em "O abolicionismo". No livro, Nabuco defende que a eliminação da escravidão, entendida como todo o sistema econômico arcaico e o regime de poder reunido em torno dos senhores de escravo, é a reforma mais urgente a ser realizada no Brasil. Para o autor, a escravidão influenciou toda a formação física, intelectual e moral da sociedade brasileira, de modo que a reforma deverá começar pelo fim do regime escravocrata, mas deverá seguir adiante, até que se apaguem todos os seus efeitos sobre o país. Para Nabuco, a própria identidade nacional estava ameaçada pelos efeitos funestos de mais de 300 anos de escravidão. A escravidão impedia a formação da pátria e da Nação. Formar uma raça livre e, principalmente, uma Nação livre por meio de uma reforma abolicionista (que estimularia a auto-organização política e a iniciativa econômica), era uma questão urgente, uma questão de sobrevivência.

Um dos grupos mais famosos do movimento de 1870 certamente é o da Faculdade de Direito de Recife. Naquela década, a faculdade foi tomada por jovens professores e estudantes que pretendiam expurgar antigos padrões em nome da civilização (Cf. SCHWARCZ, 1993). Reunido em torno de Tobias Barreto e de José Higino Duarte, animado por todo um jargão 
evolucionista retirado das teorias de Spencer, Darwin, Littré, Le Play, Le Bon, esse grupo promoveu uma crítica ferrenha ao direito natural e à monarquia, defendendo uma nova concepção de direito, mais científica, vinculada à biologia e à antropologia física (Cf. SCHWARCZ, 1993: 149). Também propôs uma nova interpretação da história nacional e da formação social brasileira a partir de uma reatualização da imagem das três raças do historiador Von Martius.

Com uma perspectiva político-intelectual relativamente próxima ao grupo da Faculdade de Direito de Recife, os positivistas abolicionistas das Escolas Militar e Politécnica do Rio de Janeiro possuíam o diferencial de ser um grupo constituído dentro da própria burocracia estatal, dentro do Exército. Decididamente, possuíam uma força política importante naquele momento. Esse grupo era composto principalmente por jovens oficiais e pela mocidade acadêmica militar. Nas duas escolas, esses rapazes encontravam não só uma formação de tipo "técnico-científico", como um ambiente marcado pelo cientificismo europeu, sobretudo, pelo comtismo. Reunidos no Clube Acadêmico Positivista e inspirados pela lei dos três estágios de Comte, acreditavam que havia um processo evolucionário em curso, seguindo na direção de um regime social industrial e republicano, e que caberia ao grupo e ao Exército garantir uma transição pacífica e ordenada para esse regime.

O principal mentor do grupo foi o professor de matemática e oficial do exército, Benjamin Constant, um dos pioneiros na difusão do comtismo e das teorias de Herbert Spencer no Brasil. Para Constant, a mocidade das escolas militares, estando munida da ciência positiva, estava habilitada a exercer sua cidadania e contribuir para o processo de evolução do país para um novo estágio social.

Por fim, o grupo dos federalistas científicos é provavelmente o grupo mais amplo do movimento de 1870 e certamente o grupo mais forte historicamente, pois reunia um imenso poderio econômico e político. Seus membros estavam reunidos em torno da Faculdade de Direito de São Paulo, do Partido Republicano de São Paulo e do Partido Republicano Riograndense, a maioria era de bacharéis oriundos dos segmentos dos cafeicultores paulistas e dos estanceiros do sul e que atacavam a centralização política da monarquia e clamavam por maior autonomia política para suas províncias. O grupo atuou com muita regularidade na imprensa e nas agremiações. Suas publicações e discursos continham uma forte "linha científica de ataque ao Império e defesa do republicanismo", pregando a direção científica dos governos e criticando o centralismo e o imobilismo do governo imperial (Cf. ALONSO, 2002: 232). Para os federalistas, o governo centralizado, patrimonialista e ineficaz do Império era 
como um corpo artificial resistente à inovação, prejudicial às províncias e ao próprio povo que não podia participar politicamente. Era necessário empreender uma série de reformas, orientadas cientificamente, no sentido de destruir esse arcabouço político e fundar um novo governo.

Uma das figuras proeminentes do grupo foi o advogado Alberto Sales (irmão de Campos Sales). Sales trabalhou ativamente na Gazeta de Campinas e no jornal A Província de São Paulo, tendo se destacado como principal ideólogo do Partido Republicano Paulista. A principal tese defendida por Sales era a ideia de que todos os governos tenderiam fatalmente para a forma científica da república "semecrática" (tradução para self-government), um governo escolhido pelo povo, de acordo com seus costumes e com suas necessidades sociais, onde o poder político é limitado pelos direitos individuais e sociais, sendo administrado por funcionários eleitos com mandato temporário e responsável. Esse regime era visto como uma imposição da evolução das instituições políticas, por ser mais adequado à representação dos interesses e características de uma nação. Também pregava a superioridade do formato federalista para um país com as dimensões territoriais e com a diversidade racial do Brasil (Cf. VITA, 1965).

Em resumo, o movimento político-intelectual de 1870, enquanto parte do processo de modernização vivido pelo Brasil na condição de país "satélite" de um sistema capitalista cada vez mais globalizado, constituiu-se a partir de segmentos sociais que eram os principais interessados na continuidade e na vitória desse processo. Tanto na condição de grupo social recém-nascido e ascendente graças a tais mudanças (burguesia agrária, novos segmentos urbanos, próprio Exército), quanto na condição de grupo de elite em trajetória economicamente descendente (Faculdades de Recife e Salvador), e mesmo como atual grupo de elite em situação de ambiguidade e ameaçam (liberais), os diferentes segmentos do movimento viviam esse momento de transformação em todos os âmbitos de suas vidas individuais e coletivas. A partir de sua própria perspectiva, cada um deles esteve engajado em uma luta política e intelectual em favor de reformas adequadas à renovação socioeconômica, à continuidade do processo de integração e à superação das crises que existiam no país, se dispondo inclusive a enfrentar ordem imperial caso ela obstaculizasse todo o processo.

Dentro do movimento, facções liberais dissidentes e associações republicanas se alinhavam com toda uma geração de jornalistas, literários, professores e estudantes através da crítica e enfrentamento da realidade social e política do país, ambicionando um programa de intervenção que pavimentaria o caminho do país rumo ao futuro que despontava do outro lado 
do Atlântico (Cf. NEEDELL, 1993: 221). Não por acaso, o centro gravitacional do movimento encontrava-se nas faculdades, que vinham operando como verdadeiros centros de politização e redistribuição dos ideais "civilizados” vindos da Europa (Cf. VITA, 1965: 8).

Para Ângela Alonso (Cf. 2002: 175), a importância das teorias europeias estava concentrada na sua força política: o repertório europeu oitocentista fornecia o instrumental teórico e retórico necessário para avaliar o cenário político-social brasileiro e propor alternativas de intervenção.

Desse modo, é necessário repetir mais uma vez: foi justamente no aspecto simbólico, ao propagar uma nova visão de mundo e pregar uma nova imagem de sociedade que, a nosso ver, o movimento de 1870 foi tão inovador. Tomado por um cenário de transformação econômica e sociocultural, informado por teorias da história evolucionistas, esse movimento difunde um projeto político de reorganização do país sustentado por um olhar científico sobre a realidade, deslocando os anseios e vontades para o futuro de um país que deveria civilizarse.

\section{A perspectiva político-intelectual da geração 1870 e a importância dos trânsitos com o repertório europeu}

Durante muito tempo vigorou a imagem difundida por intelectuais, críticos literários e historiadores de que o Brasil seria, à época, um entreposto dos produtos culturais provindos do exterior, constituindo-se como um espaço de importação e imitação das ideias estrangeiras (Cf. ORTIZ, 2006: 27). Contrário a esta perspectiva, Renato Ortiz defende a ideia de que a importação das teorias europeias envolvia uma escolha orientada a partir das necessidades internas do país: tratava-se de um processo de "sincretismo científico", onde as teorias estrangeiras eram escolhidas, ordenadas e recortadas de acordo com um "sistema-partida", a problemática nacional (Cf. ORTIZ, 2006: 30). Ângela Alonso também argumenta que aqueles intelectuais adotaram essas teorias conforme seu potencial para explicar a conjuntura brasileira. Segundo a autora, a relação entre autores brasileiros e estrangeiros era de filiação política, de modo que pensadores sociais como Comte, Spencer, Stuart Mill e Renan não eram referidos como filósofos, mas como teóricos da reforma da sociedade (Cf. ALONSO, 2002: 175).

Acreditamos que a análise do movimento de 1870, principalmente do ponto de vista da sua dimensão intelectual, deve ser um pouco mais ponderada. Ao lermos os textos dos 
intelectuais que protagonizaram o movimento, fica evidente o fato de que eles não eram meros imitadores, pois realizavam recortes e rearranjos teóricos inusitados e originais de acordo com suas preocupações políticas e nacionais, travando, inclusive, intenso diálogo com a tradição e o pensamento local. Entretanto, resumir esse processo como uma "escolha" político-intelectual (como uma simples escolha individual, na qual o ator elege recursos teóricos e retóricos mais adequados aos seus interesses políticos e intelectuais), motivada pela realidade interna do país é, a nosso ver, simplificar o problema. Afinal, a relação com o repertório político-científico europeu sempre foi mais ou menos condicionada pela imposição estrutural de um espaço de possíveis (no caso, possibilidades teóricas) que não tem nada de aleatório. A presença intensa de referências ao pensamento português, francês e inglês é bem sugestiva nesse sentido.

O argumento de Sevcenko é forte, mas inspira uma reflexão crucial sobre esse processo:

Vemos, portanto, que esse desdobramento a nível mundial da cultura europeia forçava no sentido de uma europeização das consciências e gozava da vantagem de ser o único padrão de pensamento compatível com a nova ordem econômica unificada, fornecendo, pois, o subsídio para as iniciativas de modernização das sociedades tradicionais. O caso brasileiro é típico (SEVCENKO, 1999: 82).

$\mathrm{O}$ argumento, apesar de soar radical, permite fazer uma importante consideração. O ciclo mundial de integração que se iniciou nas décadas de 1860 e 1870 não se deu apenas no âmbito econômico, como fluxo de mercadorias e modelos de produção e negócio, como também não se deu apenas no âmbito político, por meio da influência direta do imperialismo ou indireta das relações diplomáticas. Esse ciclo também se deu no âmbito sociocultural, não como um simples contato, troca ou intercâmbio cultural entre os países, mas como um importante processo de disseminação de modelos de pensamento e sentimento e de padrões de conduta ocidentais e europeus.

A partir da sociedade ocidental... padrões de conduta ocidentais 'civilizados' hoje estão se disseminando por vastas áreas fora do ocidente, seja através do assentamento de ocidentais ou através da assimilação pelos estratos mais altos de outras nações (...). Essa difusão dos mesmos padrões de conduta... seguiu-se à incorporação de outros territórios à rede de interdependências políticas e econômicas à esfera das lutas eliminatórias entre as nações do Ocidente (...). As formas 'civilizadas' de conduta disseminaram-se por essas outras áreas em razão e na medida que nelas, através de sua incorporação à rede cujo centro ainda é o Ocidente, a estrutura de suas sociedades e de

\section{Aitistorias}


relacionamentos humanos também está mudando (ELIAS, 1993: 212).

Esses modelos e padrões socioculturais ocidentais e europeus foram assimilados e incorporados pelos grupos locais de modo mais ou menos inconsciente e com maior ou menor facilidade, fundindo-se com os padrões socioculturais da sociedade local com maior ou menor sucesso.

Podemos notar... características de uma forma primitiva de ascensão, não ainda no grupo nativo como um todo, mas de alguns de seus membros. Eles absorvem o código dos grupos superiores e passam, assim, por um processo de assimilação. Seu controle de paixões, sua conduta, obedecem às regras dos grupos superiores. (...) Pessoas nessa situação tentam conciliar e fundir esse padrão com os hábitos e tradições de sua própria sociedade. (ELIAS, 1993: 259).

Assim como os próprios intelectuais europeus, mas de uma perspectiva muito diferente (a partir de uma posição "dominada" e "defasada"), os intelectuais do movimento de 1870 assistiram, vivenciaram e, principalmente, incorporaram todo esse processo de integração econômica, política e sociocultural que se estendeu por todo o globo terrestre ao longo da segunda metade do século XIX. Como já foi dito, o movimento de 1870 foi produto histórico e vetor sociopolítico desse processo no Brasil, enquanto seus intelectuais foram os mais consequentes porta-vozes, e mesmo profeta local, do desenvolvimento incontornável desse processo mundial de integração modernizadora, cujo ritmo e intensidade ameaçavam a própria sobrevivência de quem não o acompanhava.

Nesse sentido, não se trata apenas de imitar e importar ou escolher e sincretizar modelos de pensamento ou teorias, a própria experiência no mundo, a própria constituição cognitiva e afetiva desses atores era profundamente marcada por todo esse processo. Alguns viveram e estudaram na Europa e nos Estados Unidos, viram de perto o centro do processo e o novo mundo que ali surgia. Outros estudaram com professores que conheciam os ideais e teorias que de lá chegavam, quando não estava no próprio parlamento presenciando a crise e os desafios que assolavam a agenda política do país. Consequentemente, as suas tendências e "escolhas" político-intelectuais encontravam quase que "espontaneamente" os "mestres" ou "páreos" intelectuais europeus que escreveram sobre o mundo a partir de uma experiência equivalente, paralela, mas obviamente muito diferenciada. Um encontro que se dava por meio de uma integração sociocultural que não tinha nada de "equilibrada" ou "justa", além de ser defasada, de modo que tudo acontecia dentro de um escopo bem definido e não aleatório de 
possibilidades fundamentado em imposições estruturais. Além disso, esse encontro ainda era influenciado por padrões de conduta europeu-ocidentais que já vinham se fundindo com as estruturas de personalidade locais.

Assim, acreditamos que qualquer análise do movimento de 1870 deve atentar para essa dinâmica complexa, centrada em um processo histórico de integração modernizadora que se constituía como experiência (formativa dos atores, forjando aspirações e dilemas individuais e coletivos) e como temática (objeto de análise, avaliação e preocupação), envolvendo um contexto que variava entre a imposição estrutural de um espaço de possíveis, a influência de princípios de preferência já mais ou menos fundidos aos padrões europeus, e a escolha por relações de afinidade.

As doutrinas europeias que aqui chegavam, portavam teorias da história e filosofias sociais e políticas que possibilitavam, por conta das relações estruturais objetivas e subjetivas de que falávamos a compreensão do quadro de transformação socioeconômica e política vivida pelo Brasil, além de oferecerem uma possibilidade de intervenção e mesmo predição desses processos. Os intelectuais brasileiros formaram-se em meio a esse quadro, experienciavam na vida política, intelectual, pública ou privada, de modo individual ou coletivo, um período de mudanças e crises que, como eles percebiam muito bem, estava conectado à nova realidade que despontava nos dois lados do atlântico norte. Uma realidade tida como civilizada e evoluída e que agora batia à porta do país. As doutrinas europeias, como o positivismo e o evolucionismo social, lhes permitiam enquadrar cognitiva e afetivamente todo esse cenário que os arrebatava por dentro, por fora e por todos os lados.

\section{O repertório político-intelectual europeu da segunda metade do séc. XIX}

O repertório político-intelectual europeu da segunda metade do século XIX fora produzido em meio à consolidação das principais nações europeias como centros mundiais de modernização. Uma espécie de berço da civilização industrial-científica burguesa que agora, completado o ciclo iniciado pelas revoluções industrial e francesa que derrubou o mundo medieval, se lançava sobre todo o globo através da expansão imperialista subsidiada pela II Revolução Industrial. Por outro lado, o grande respaldo teórico e empírico que as ciências naturais ganhavam naquele momento, enquanto responsáveis por parte das mudanças e progressos em curso, repercutia profundamente nas doutrinas que se propunham a interpretar o mundo à luz de todo esse processo que envolvia o fim do mundo medieval, o despontar da 
civilização burguesa e a centralidade adquirida pelo Ocidente (Cf. AZEVEDO, 1994: 16).

Foi mais ou menos nessas condições que o positivismo, o darwinismo social e o evolucionismo social, além de outras tendências, surgiram como parte de um imaginário cientificista e materialista voltado para a compreensão da realidade à luz desse cenário de integração modernizadora e civilizatória de proporções mundiais. Um imaginário que tomava todo esse processo como um destino histórico, movido por leis naturais (ou mesmo biológicas) que só eram passíveis de compreensão e avaliação através da ciência. Em suma, a "civilização" era uma lei, um destino inevitável a ser compreendido e buscado com ajuda da razão.

Como analisado por Norbert Elias, a palavra "civilização" ganha corpo através do movimento reformista dos fisiocratas franceses. Atuando como burocratas nos últimos reinados do Antigo Regime francês, os fisiocratas propunham a ideia de que a sociedade e a economia tinham leis próprias que resistiam à interferência irracional dos governantes. Segundo Elias (Cf. 1994: 60), essas leis correspondiam basicamente aos processos de crescente comercialização e industrialização que despontavam na Europa. Assim, esses burocratas defendiam que o governo deveria adequar-se a essas leis naturais através de uma administração esclarecida, sob a pena de deflagrar o caos. Era preciso reformar as instituições e a legislação, aprimorá-las através do conhecimento, para garantir a continuidade, de forma ordenada, desse processo natural de progresso material (Cf. ELIAS, 1994: 59).

Vinculado à adaptação burguesa da ideia cortesã de civilité, que designava a conduta e o modo de ser refinado da classe superior, o conceito de civilização surge como designação de um processo natural de progresso material e do consequente refinamento, melhoria e racionalização das instituições sociais e políticas, além dos modos de comportamento.

De acordo com Elias, com a ascensão da burguesia francesa, o conceito de civilização passa a expressar a autoimagem nacional francesa, não demorando muito para também ser utilizado como autoproclamação da superioridade francesa, justificando aspirações expansionistas já no governo de Napoleão (Cf. ELIAS, 1994: 64). Gradualmente, a consciência de civilização como consciência de superioridade começou a se espraiar pelas nações europeias e passou a expressar a consciência que a Europa tinha de si mesma e, mais tarde, que o Ocidente tinha de si mesmo (Cf. idem, ibidem: 23). Com o crescimento da ação expansionista por parte dessas nações na segunda metade do século XIX, durante o chamado imperialismo, a consciência de civilização passou a servir como justificativa para o seu domínio direto ou indireto sobre grandes segmentos do mundo não-europeu (Cf. idem, 
ibidem: 64).

Chega a ser intrigante o modo como o conceito de civilização, tanto na sua formulação teórica e fisiocrática como um processo natural em curso, quanto na sua formulação política e imperialista como um estado de superioridade que legitimaria ações expansionistas, encontrase reproduzido nas doutrinas cientificistas da segunda metade do século XIX. A grande novidade dessas doutrinas foi o acoplamento desse conceito com as novas perspectivas formuladas pelas ciências naturais, particularmente a biologia e as novas teorias da evolução. Como coloca Ortiz:

Elaboradas na Europa em meados do século XIX, essas teorias, distintas entre si, podem ser consideradas sob um aspecto único: o da evolução histórica dos povos. Na verdade, o evolucionismo se propunha a encontrar um nexo entre as diferentes sociedades humanas ao longo da história; aceitando como postulado que o 'simples' (povos primitivos) evolui naturalmente para o mais 'complexo' (sociedades ocidentais), procurava-se estabelecer as leis que presidiriam o progresso das civilizações. (...) o evolucionismo, em parte, legitima ideologicamente a posição hegemônica do mundo ocidental. A 'superioridade' da civilização europeia torna-se assim decorrente das leis naturais que orientariam a história dos povos (ORTIZ, 2006: 15)

Essas doutrinas acreditavam que havia um processo evolucionário natural em curso, comum a todas as sociedades, partindo de um estágio social inferior para um estágio social superior. Um processo natural, de cunho civilizatório, que levaria todas as sociedades até o estágio no qual se encontravam as sociedades europeias, com tudo o que ele envolvia: um regime republicano, industrial e científico.

Dentre essas doutrinas, o positivismo de Auguste Comte e o evolucionismo social de Herbert Spencer chegaram com extrema força na América Latina e no Brasil, constituindo-se como o núcleo-base do pensamento político-intelectual aqui desenvolvido. Os intelectuais brasileiros combinavam a lei dos três estágios de Comte com a perspectiva da evolução por integração e diferenciação de Spencer, além de ajustarem a política científica comtiana à defesa do estado industrial, pacificado e liberal promovida pelo filósofo inglês. A base de sua perspectiva era a crença em uma evolução social linear, na qual o modelo de pensamento metafísico e a organização centralizada e coercitiva de tipo militar seriam substituídos, através da intervenção de um governo orientado cientificamente, por um pensamento científico e uma organização de tipo industrial, liberal e pacificada (Cf. LEMOS, 1999: 357; VITA, 1965: 36). 


\section{A perspectiva político-intelectual da geração de 1870}

Nas publicações e discursos do movimento de 1870, encontramos uma interpretação do processo de integração e modernização que chegava ao Brasil como um processo evolucionário (determinado por leis naturais) rumo à civilização, sendo marcado por crises morais e sociais relativas às contradições da transição de um estágio social anterior e inferior para um estágio novo e superior que poderiam ser evitadas por reformas político-sociais orientadas pela ciência, único instrumento legítimo de compreensão das leis que moviam a realidade.

A formação intelectual e política forjada em meio a esse processo de integração modernizadora e à respectiva crise da ordem imperial, combinada com as doutrinas europeias e o seu binômio civilização e ciência, levou boa parte dos intelectuais e políticos do movimento de 1870 a construir algumas constatações padrões sobre a realidade brasileira. $\mathrm{O}$ princípio de todo o diagnóstico era a ideia de que uma mudança inevitável ocorria no mundo todo. As sociedades estariam em um momento crítico do processo evolutivo no qual elas transitariam de uma forma militar, aristocrática e medieval para uma forma caracterizada pelo desenvolvimento econômico, pela complexidade social, pela expansão da participação política e pela racionalização do Estado, além da substituição da religião pela ciência enquanto orientação normativa da conduta (Cf. ALONSO, 2002: 239).

Como apontado por Ortiz (Cf. 2006: 15), o diagnóstico da realidade brasileira a partir de uma história natural da humanidade definia de imediato o nosso estágio civilizatório como inferior, muito distante da etapa alcançada pelos países europeus. A constatação era de que o Brasil ainda era uma formação aristocrática e medieval, muito atrasada com relação às sociedades modernas que despontavam na Europa, com seus Estados e economias poderosas. A partir desse diagnóstico, a consciência do atraso seria uma marca do pensamento do movimento de 1870. É nesse sentido que Tobias Barreto, diante do estado de pauperismo e desagregação social das cidades do interior, dizia que o Brasil ainda não era uma nação (Cf. BARRETO, 1926: 101). Para essa geração de pensadores, era preciso remodelar a estrutura social e política do país, modernizá-la, para que este pudesse figurar entre as nações civilizadas.

Como observa Alonso em um comentário sobre essa geração: "a política científica deu-lhes um parâmetro, a escala evolutiva, para comparar o desempenho do país com o que julgavam ser um movimento universal (...). A história brasileira foi reavaliada, revelando a 
incompatibilidade entre a sociedade imperial... e a civilização moderna" (ALONSO, 2002: 241). O diagnóstico de 1870 interpretava a especificidade do cenário brasileiro como uma diferença de fase, apreendida a partir de uma teleologia histórica e de uma filosofia social progressista que esclareciam o nosso estágio de atraso e, ao mesmo tempo, definiam o programa de intervenção necessário para superá-lo. Nesse quesito, a influência comtiana era generalizada: o melhor programa de intervenção seria a realização, pelo Estado, de um conjunto de reformas sociais e políticas orientadas pela ciência.

A partir da perspectiva comtiana, o governo aparecia como uma questão de competência intelectual e técnica: somente uma intelligentsia bem instrumentalizada seria capaz de agir em nome do bem comum. A transição para um estágio social moderno deveria ser orientada por uma elite político-intelectual habilitada por sua familiaridade com o conhecimento científico e por sua capacidade de compreender e analisar a realidade brasileira (Cf. SALES apud VITA, 1965: 89).

A geração intelectual de 1870 não hesitou em se auto reconhecer como essa elite político-intelectual responsável por sintonizar o país com a marcha da civilização. Logo procedeu à realização de duas etapas incontornáveis da transição moderna guiada pela política científica. Na primeira etapa, procurou diagnosticar a realidade histórica singular do país, tentando identificar as possíveis causas do atraso e os impasses que provocavam as crises de transição. Na segunda, a partir do diagnóstico feito, propôs uma série de caminhos possíveis para que o Brasil se constituísse como um país civilizado, um conjunto de reformas sociais e políticas necessárias para superação do estágio de atraso e transformação do país: reforma do Estado e das instituições políticas (extensão dos direitos civis, da liberdade civil, religiosa e de imprensa; secularização do Estado; expansão do voto; descentralização política), reforma da economia (abolição completa da escravidão e adoção do regime de trabalho livre; adoção de modelos de produção e negócio capitalistas), reforma educacional (expansão do ensino), etc.

Como já dissemos, o caráter inovador do movimento de 1870 está justamente no seu aspecto simbólico, ao portar uma visão de mundo que rompia com a visão romântica e católica da ordem imperial. Por mais que houvesse um diálogo e uma ressemantização de elementos imperiais ou coloniais, a visão de mundo cientificista e materialista do movimento transformou o próprio modo de compreensão e avaliação da ordem política e social, o que reverberava na proposição de uma nova imagem de sociedade.

Com a formulação da tese de que a economia e a sociedade seguiriam suas próprias

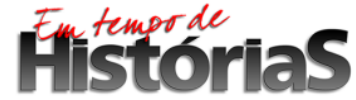


leis e, subsequentemente, com a formação do conceito mais amplo de "civilisation", surge na Europa da passagem do século XVIII para o século XIX, uma perspectiva teórico-política cada vez mais forte que tomava as leis autônomas do mundo histórico como objetos produtores de verdade, como parâmetros de verificabilidade que permitiriam julgar uma prática governamental como certa ou não (Cf. FOUCAULT, 2008: 45). Ou seja, configuravam-se como base de legitimação de uma ordem política e social na medida em que esta deveria se adequar à fatalidade incontornável daquelas, sob a condição de tornar-se um obstáculo e, assim, ameaçar sua própria razão de ser (Cf. FOUCAULT, 2008: 61). A legitimidade do domínio sociopolítico passaria por sua capacidade de adequação a tais leis por meio de instrumentos de avaliação capazes de apreendê-las e codifica-las, o que naquele momento era associado à ciência. Movido por essa perspectiva, o movimento de 1870 introduziu uma grande novidade como paradigma do pensamento político brasileiro de fins do século XIX: a crença de que qualquer projeto de domínio político-estatal só poderia ser bemsucedido quando fundamentado no conhecimento sobre a realidade produzido pela ciência. Assim, todo projeto de reorganização do Estado-nacional brasileiro estaria necessariamente ligado às atividades de uma elite técnica e científica que garantiria uma orientação "verdadeira" para o projeto. O próprio aparato estatal era concebido como um aparelho técnico-burocrático a ser liderado por mentes competentes (o governo da inteligência). Mais do que advogar a importância dos intelectuais para o sucesso dos governos, essa nova visão de sociedade deslocava a ciência para o centro do mecanismo de legitimação da ordem política e social.

Além disso, essa visão, ao ter como fundamento um paradigma teleológico da evolução rumo à civilização, portava a crença na capacidade da ciência de prever e do Estado de acelerar o processo em andamento. Nesse sentido, podemos falar de uma visão de sociedade de tipo "moderna" pois para ela, mais importante que as realizações no passado que pavimentaram o caminho para um presente vitorioso, são as possibilidades de realização de um futuro glorioso. A instauração do novo e a garantia do futuro são as suas metas, de modo que o domínio no presente passa a ser legitimado pela capacidade de realizar um dever-ser, o devir histórico da civilização. Essa visão subverte o mecanismo de legitimação tradicional, pautado no passado, propondo um modelo ideológico, no qual o poder se projeta para o futuro. A visão de mundo de 1870 deslocava o centro do mecanismo e a própria maneira de conceber o mundo social para o paradigma da união entre mercado, Estado e ciência. Mais especificamente, o que estava em pauta era a efetivação desse paradigma em um futuro 
próximo, por meio de um projeto político, orientado racionalmente, que viabilizasse a reorganização da sociedade brasileira nos moldes das civilizações europeias. Os intelectuais do movimento de 1870, movidos por essa visão de mundo e de sociedade, assumiram sua missão civilizatória independentemente da solicitação do governo imperial, procedendo ao diagnóstico da realidade política, social e econômica do país com o objetivo de desvendar o que mantinha o país em posição tão distante dos países europeus e o que obstaculizava o avanço do processo de civilização. A questão fundamental era entender o que impedia o Brasil de se constituir como uma sociedade-nação civilizada e qual o programa de reformas necessário para realizar tal meta.

\section{Conclusão}

Como dissemos, para entender o movimento de 1870, é preciso atentar para essa dinâmica complexa, centrada em um processo histórico de integração modernizadora que se constituía como experiência e como temática daquela geração. O desenvolvimento de sua perspectiva político-intelectual se deu através de trânsitos complexos e multivariados com o repertório intelectual-filosófico-europeu, dentro de um contexto global de integração. Esses intelectuais procuraram inserir o Brasil numa história evolucionária, lendo o momento conturbado do país como uma crise de transição na direção da civilização moderna e que deveria ser regrada por uma política científica guiada por uma vanguarda ilustrada. Através dos recursos teóricos das teorias europeias, procuravam entender a singularidade histórica brasileira e os entraves que mantinham o país em situação de atraso.

Assim, o caráter inovador do movimento e sua relação com o repertório europeu não podem mais ser simplificados enquanto um mero processo de recepção e imitação. Mesmo a ideia de uma escolha motivada por questões políticas é insuficiente para dar conta desse processo de trânsito intelectual e cultural. A experiência desses atores estava marcada pelo processo de modernização vivido pelo país, perpetrado pela II Revolução Industrial, o que repercutiu profundamente na construção da sua perspectiva político-intelectual e na forma como ela interagiu com o repertório intelectual europeu.

Fica claro como a imagem de mundo "moderna" e o respectivo projeto civilizatório nacional que animaram a geração político-intelectual de 1870 estavam diretamente relacionados à vivência e à autoconstituição daquele grupo a partir de um processo de integração transatlântica prenhe de relações complexas e multifacetadas, com fronteiras 
difíceis de definir, e que pouco tinha a ver tanto com a noção de imitação quanto com a tese de uma escolha teórico-política. O movimento de 1870 foi simultaneamente efeito histórico e agente perpetrador desse processo de integração no Brasil, na medida em que seus integrantes anunciaram performatizaram e lutaram movidos pela imagem de um desenvolvimento civilizatório de caráter global. Uma complexa rede de trânsitos que variava entre a imposição estrutural de um espaço de possibilidades teóricas, políticas e culturais, a influência de esquemas de preferência já de alguma forma ligados aos padrões europeus e, finalmente, a escolha intencional por relações de afinidade.

\section{Referências Bibliográficas}

ALONSO, Ângela. Ideias em movimento: a geração 1870 na crise do Brasil império. São Paulo: Paz e Terra, 2002.

AZEVEDO, Fernando de. As ciências no Brasil. Rio de Janeiro: Universidade Federal do Rio de Janeiro, 1994. v.1.

BARRETO, Tobias. Discursos. Rio de janeiro: Pongetti, 1926.

CARDOSO, Fernando Henrique. "Dos governos militares a Prudente - Campos Sales". In: FAUSTO, Boris (org.). O Brasil Republicano: estrutura de poder e economia (1989-1930). Rio de Janeiro: Bertrand Brasil, 1996.

ELIAS, Norbert. O Processo Civilizador: 2. Trad. Ruy Jungmann. Rio de Janeiro: Jorge Zahar, 1993. O Processo Civilizador. Trad. Ruy Jungmann. Rio de Janeiro: Jorge Zahar, 1994.

FOUCAULT, Michel. Nascimento da biopolítica. Trad. Eduardo Brandão. São Paulo: Martins Fontes, 2008.

LEMOS, Renato. Benjamin Constant: vida e história. Rio de Janeiro: Topbooks, 1999.

NEEDELL, Jeffrey David. Belle époque tropical: sociedade e cultura de elite no Rio de Janeiro na virada do século. São Paulo: Companhia das Letras, 1993.

ORTIZ, Renato. Cultura brasileira e identidade nacional. São Paulo: Brasiliense, 2006.

SCHWARCZ, Lilia Moritz. Espetáculo das raças: cientistas, instituições e questão racial no Brasil 1870-1930. São Paulo: Companhia das Letras, 1993.

SEVCENKO, Nicolau. Literatura como missão: tensões sociais e criação cultural na primeira república. São Paulo: Companhia das Letras, 1999.

VITA, Luís Washington. Alberto Sales: Ideólogo da República. São Paulo: Companhia Editora Nacional, 1965. 